\title{
Female Pattern Hair Loss: a clinical and pathophysiological review*
}

\author{
Paulo Müller Ramos ${ }^{1}$ \\ Hélio Amante Miot ${ }^{1}$
}

DOI: http:/ / dx.doi.org/10.1590/abd1806-4841.20153370

\begin{abstract}
Female Pattern Hair Loss or female androgenetic alopecia is the main cause of hair loss in adult women and has a major impact on patients' quality of life. It evolves from the progressive miniaturization of follicles that lead to a subsequent decrease of the hair density, leading to a non-scarring diffuse alopecia, with characteristic clinical, dermoscopic and histological patterns. In spite of the high frequency of the disease and the relevance of its psychological impact, its pathogenesis is not yet fully understood, being influenced by genetic, hormonal and environmental factors. In addition, response to treatment is variable. In this article, authors discuss the main clinical, epidemiological and pathophysiological aspects of female pattern hair loss.
\end{abstract}

Keywords: Alopecia; Androgens; Epidemiology; Hair; Hair Follicle; Miniaturization; Women

\section{INTRODUCTION}

Etymologically, the word "alopecia" comes from the Greek $\dot{\alpha} \lambda \omega \dot{\pi} \eta \xi$ (aloppex) , which means "fox". It is an allusion to the constant hair loss suffered by these animals during life. According to the BrazilianPortuguese Spelling Vocabulary (VOLP), alopecia should not be marked with an accent (paroxytone stress) due to the influence of Latin (alopecia). The term is also registered this way among the health science descriptors (DECS) for scientific indexing in Brazil. ${ }^{1-3}$

The description of the classical clinical pattern of baldness in men is known since antiquity. As an example, we may cite Hippocrates' (400 BC) observation that eunuchs did not develop baldness. Later, Joseph Plenck, in his book "D octrina de M orbis Cutaneis" (Vienna, 1776) (Vienna, 1776) identified, in these cases, the miniaturization of hair follicles, which he called "calvities". He also distinguished the disease in two ways, according to its extension: universalem e partialem; and in ten ways according to its cause: febrisequa, puerperarum, morborum exantematicorum, acrimoniosa, phtisicorum, a debilitate nervosa, fenum, hereditaria, a vapore mercurii and a caufa externa. ${ }^{4}$ However, the diffuse balding process (affecting mainly women) still causes confusion in its nomenclature nowadays. ${ }^{5}$

Initially, the term "diffuse alopecia in women" was widely used to characterize the disease. ${ }^{6,7}$ After 1942, when Hamilton demonstrated of the involvement of male hormones in the development of classic pattern baldness in men, the term androgenetic alopecia was established to emphasize the hormonal and genetic factors associated with the development of the disease. ${ }^{8,9}$ Because diffuse pattern alopecia (which often affects women) was thought to be a variant of the same entity, the term female androgenic alopecia or female pattern baldness, started to be used. ${ }^{7}$

Although the follicular changes that lead to alopecia are similar between men and women, clinical presentation and response to antiandrogen therapy are different. In addition, the participation of androgens in the development of female pattern baldness has not yet been fully elucidated. Given these differences in relation to male pattern baldness, the term Female Pattern Hair Loss (FPHL) has been preferred over female androgenic alopecia. ${ }^{5}$ In this paper, we adopt the term FPHL to name baldness in women and male

Received on 13.01.2014.

Approved by the Advisory Board and accepted for publication on 26.05.2014

Study conducted at the Department of Dermatology and Radiology, Botucatu Medical School - Sao Paulo State University Júlio de Mesquita Filho (FMBUnesp) - Botucatu (SP), Brazil.

Financial Support: This project funded by the FUNADERSP.

Conflicts of Interest: None

Sao Paulo State University “Júlio de Mesquita Filho” (Unesp) - Botucatu (SP), Brazil.

C 2015 by Anais Brasileiros de Dermatologia 
pattern alopecia (MPA) to name baldness in men. Despite this division, women may eventually present baldness similar to the male pattern and vice versa.

FPHL is characterized as a non-scarring diffuse alopecia, evolving from the progressive miniaturization of hair follicles and subsequent reduction of the number of hairs, especially in the central, frontal and parietal scalp regions (Figure 1). ${ }^{10}$

FPHL is the condition that most commonly leads to hair loss in adult females. Its prevalence increases with age and the disease shows an inconsistent response to treatment. ${ }^{11}$ These elements compromise body image and strongly affect self-esteem, negatively impacting the patients' quality of life.

\section{EPIDEMIOLOGY}

Hair loss and hair thinning complaints are common in dermatological practice. According to a census conducted by the Brazilian Society of Dermatology in 2006 with 36,253 female patients, nonscarring alopecia (unspecified) was one of the ten most common diagnoses. ${ }^{14}$

The frequency of FPHL varies among population groups and increases with age. However, a comparison between prevalence studies is hampered by the lack of universally accepted criteria for the diagnostic definition of the disease. ${ }^{10}$

In general, FPHL has its onset during the reproductive years. More severe cases of the disease are already noticeable at puberty. However, there is a greater demand for treatment among patients aged 25-40 years. There is a second peak incidence at menopause, between 50 and 60 years of age. 10,15,16

Since the disease has a slow and progressive course, studies considering only clinical criteria usually identify cases with marked reduction of hair volume and show modest prevalence among young

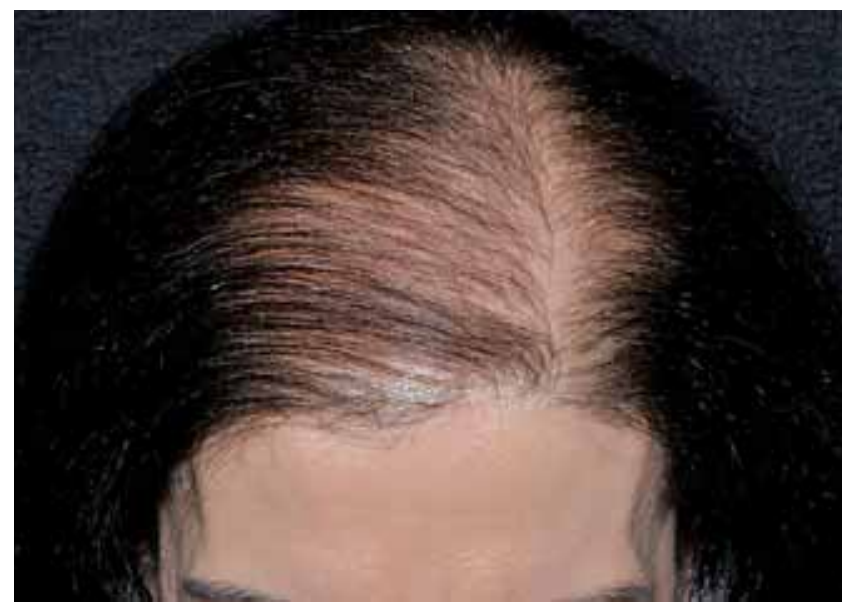

Figure 1: Female Pattern Hair Loss. Diffuse thinning of the hairs in the frontal and parietal regions, preserving the anterior hair implantation line people. Nevertheless, if more sensitive diagnostic procedures, such as dermoscopic identification of hair miniaturization, start to be used, the prevalence of FPHL might become higher in all age groups. ${ }^{17}$

In 2001, a US study conducted with 1,008 Caucasoid women revealed a $3 \%$ prevalence in the third decade of life. Prevalence showed a gradual increase with age, reaching $32 \%$ in the ninth decade of life. Overall prevalence was $19 \% .^{18}$

In 2001, a study conducted in England with 377 patients showed a $6 \%$ prevalence among women under 50 years of age. The highest prevalence was found among women over 70 years of age: $38 \% .^{19}$

In 2005, an Australian study conducted with 717 women found a $13 \%$ prevalence in the third decade of life, and a 54\% prevalence in the eighth decade of life. Overall prevalence was $32 \%{ }^{20}$

A study conducted with 4601 Korean women in 2001 found an overall prevalence of $5.6 \%$ and progressively higher frequencies with increasing age. ${ }^{21}$

In 2010, a population study involving 8446 Chinese women found similar prevalence rates to the ones found in the Korean study. ${ }^{22}$

A recent study conducted in Taiwan with 26,226 women showed lower overall prevalence of FPHL in Caucasoids. However, FPHL prevalence in Caucasoid women was still higher than in Korean or Chinese women. ${ }^{23}$ In addition to prevalence, the study also sought to identify possible risk factors associated with FPHL. The authors found a positive association between FPHL and body mass index $>26 \mathrm{~kg} / \mathrm{m}$ (OR $=1.1)$, fasting glucose $>110 \mathrm{mg} \%(\mathrm{OR}=1.1)$, puberty before 16 years of age $(\mathrm{OR}=1.2)$, lower $(\leq 3)$ number of births $(\mathrm{OR}=1.2)$, use of oral contraceptives for more than one year $(\mathrm{OR}=1.2)$ and sun exposure for more than 16 hours per week (OR: 1.2). However, women who had breastfed $(\mathrm{OR}=0.9)$, avoided sun exposure $(\mathrm{OR}=0.8)$ or had menstrual cycle shorter than 35 days $(\mathrm{OR}=0.9)$ were less likely to develop the disease. These data suggest that higher exposure to estrogen may positively correlate with FPHL, which suggests a potential epigenetic control of FPHL. ${ }^{23}$

To date, there are no population studies on the prevalence of FPHL in African and Brazilian women.

Table 1 summarizes the weighted results of different studies on the prevalence of FPHL in Caucasoid and Asian women, according to age. These studies show a higher frequency in Caucasoid women at all ages. ${ }^{18-23}$

Although most patients with FPHL do not display other signs of hyperandrogenism, FPHL is associated with hyperandrogenic conditions, the most common being the polycystic ovary syndrome (PCOS). ${ }^{24}$ In a study conducted in England in 2003, 89 women with FPHL were evaluated and compared to a 
Table 1: Prevalence of Female Pattern Hair Loss in each age group, according to epidemiological studies in different population groups.

\begin{tabular}{|c|c|c|c|c|c|c|c|c|}
\hline \multirow[t]{2}{*}{ Study } & \multirow[t]{2}{*}{ Country } & \multirow[t]{2}{*}{$\mathbf{n}$} & \multicolumn{6}{|c|}{ Age groups* } \\
\hline & & & $20-29^{\#}$ & $30-39^{\#}$ & $40-49^{\#}$ & $50-59^{\#}$ & $60-69^{\#}$ & $>69^{\#}$ \\
\hline Norwood, 2001 & USA & 1008 & 3 & 17 & 16 & 23 & 25 & 29 \\
\hline Birch, 2001 & England & 377 & 3 & 10 & 5 & 14 & 33 & 38 \\
\hline Gan, 2005 & Australia & 717 & 12 & 17 & 25 & 28 & 41 & 56 \\
\hline Wang, 2010 & China & 8446 & 1 & 2 & 5 & 8 & 10 & 12 \\
\hline Pai, 2001 & South Korea & 4601 & - & 2 & 4 & 7 & 12 & 25 \\
\hline Su, 2013 & Taiwan & 26226 & - & 6 & 10 & 12 & 13 & 15 \\
\hline
\end{tabular}

* age in years; \# approximate percentage of patients with FPH L in each age group

control group. Among those patients with FPHL, 67\% were diagnosed with PCOS, compared to $27 \%$ in the control group

Although FPHL more frequently manifests in adulthood, it may also occur in childhood and adolescence. In 2004, Tosti and colleagues reported 20 cases of children aged between 6-10 years (12 of whom were girls) with diffuse-pattern androgenetic alopecia. None of them had laboratory abnormalities, however, they all had strong family history. ${ }^{26} \mathrm{~A}$ case series involving 43 children ( 8 of whom were girls) aged between 12 and 18 years also described a high level of family involvement. Only one subject experienced hormonal changes. ${ }^{27}$

There is evidence that FPHL has a phenotype independently associated with insulin resistance and atherosclerosis. The causal model for this finding has not yet been established, but it may be related to a hyperandrogenic state induced by insulin resistance, which also favors atherosclerosis. ${ }^{28-30}$

A case-control study conducted in Spain in 2011 evaluated 240 subjects (60 men and 60 women with hair loss and 120 controls without alopecia). The authors found an association between early onset of baldness ( $<35$ years of age), hyperglycemia, diabetes and low levels of SHBG. SHBG also showed to be an independent predictor of hyperglycemia in patients with alopecia, even after adjustment for waist circumference, gender and testosterone level (OR = 3.35). There was no association between low levels of SHBG and hyperglycemia in the controls. ${ }^{31}$

In order to investigate the relationship between baldness and metabolic syndrome, an epidemiological study was conducted in Korea in 2012. 1701 women and 1707 men were evaluated. Women with metabolic syndrome had higher prevalence of FPHL when compared with women without FPHL $(\mathrm{OR}=1.7)$.
This relationship, however, was not observed in the male population, which suggests that follicle miniaturization in FPHL and MPA arises from different stimuli. ${ }^{32}$ On the other hand, in patients without metabolic syndrome, no relationship was found between FPHL and insulin resistance..$^{33}$

An epidemiological study conducted in 2013 in Taiwan with 7,252 subjects of both sexes showed that FPHL and MPA are independent risk factors for cardiovascular disease mortality $(\mathrm{HR}=2.3)$ and diabetes mellitus $(\mathrm{HR}=3.0){ }^{34}$

Similarly, a study conducted in 2005 in Iran with 51 women with coronary artery disease (CAD) and 55 controls who underwent coronary angiography found an association between FPHL and CAD $(\mathrm{RR}=1.26) .{ }^{35}$

Another case-control study conducted in Spain with 37 patients with FPHL and 37 controls showed a higher prevalence of carotid atheromatous disease $(\mathrm{OR}=4.2)$ and metabolic syndrome $(\mathrm{OR}=10.7)$ in cases than in controls. ${ }^{36}$

\section{PATHOPHYSIOLOGY}

The pathophysiology of FPHL is not yet completely understood. There is evidence that genetic, hormonal and possibly environmental factors are involved. ${ }^{37}$

The biological cycle of the hair follicles is not synchronized among the adjacent units, assuming a mosaic pattern in the scalp. It is didactically divided into three phases: anagen (growth phase), catagen (regression) and telogen (resting phase). At the end of the telogen phase, the original hair falls out (exogenous phase) and is replaced by a new hair at early growth stage. Normally, the anagen phase lasts between 2 and 8 years; the catagen phase last between 2 and 3 weeks, and the telogen phases lasts about 3 months. ${ }^{38}$

Thus, in a normal adult scalp, there are around 
$80-90 \%$ of hair in the anagen phase, $10-20 \%$ in the telogen phase and $1-2 \%$ in the catagen phase. This can be evidenced by trichogram or anatomopathological examination. ${ }^{17}$

In FPHL there is a reduction in the duration of the anagen phase and a miniaturization of the dermal papilla (thinning of the hair). Thick pigmented hairs are gradually replaced by miniaturized hairs (Figure 2). Moreover, there is a delay between the end of the telogen phase and the beginning of the new anagen phase $^{39}$ This resting phase, during which the hair follicle remains empty, is known as the kenogen phase ${ }^{40}$ There is a gradual decrease in capillary density in the affected areas. Although FPHL and MPA have clinical presentations with different patterns, these changes also occur in MPA.

The hair follicle is a complex structure in constant activity. An imbalance between various growth factors and cytokines which mantain the anagen phase and promote apoptosis can determine the beginning of the catagen phase (Chart 1). ${ }^{41-48}$

The diffuse apoptosis of the follicular keratinocytes leads to the follicular regression observed in the catagen phase. The premature termination of the anagen phase is a landmark event in the development of FPHL. ${ }^{39}$

Apoptosis can be triggered in two ways: by the extrinsic pathway, through specific binders to a membrane receptors group from the superfamily of necrosis factor receptors; or by the intrinsic pathway, which may result from a loss in adhesion between keratinocytes, a decrease in growth factors, among other flags. ${ }^{49}$

In the hair follicle, the apoptosis starts in the melanogenic area (late anagen), propagates to the array (premature catagen) and then to the internal and external root sheath. ${ }^{50,51}$
Chart 1: Main factors associated with the transition from the anagen hair phase to the catagen hair phase.

\begin{tabular}{|ll|}
\hline Anagen-promoting factors & $\begin{array}{l}\text { Factors promoting } \\
\text { follicle apoptosis }\end{array}$ \\
bFGF & FGF5 \\
FGF7 & IL-1 $\alpha$ \\
HGF & PGD2 \\
IGF-1 & TGF- $\beta 1$ \\
PGE2 & TNF- $\alpha$ \\
VEGF & \\
Wnt & \\
\hline
\end{tabular}

bFGF, basic fibroblast growth factor; FGF5, fibroblast growth factor 5; FGF7, fibroblast growth factor 7; HGF, hepatocyte growth factor; IGF-1, insulin-like growth factor-1; IL-1 $\alpha$, interleukin-1 alpha; PGD2, prostaglandin D2; PGE2, prostaglandin E2; TGF- $\beta 1$, transforming growth factor beta1; TNF- $\alpha$, tumor necrosis factor $\alpha$; VEGF, growth factor of the vascular endothelium; Wnt, Wnt signaling pathway.

Apoptosis in the various sites of the hair follicle present different forms of regulation. The direct role of cytokines and growth factors in the control of the apoptosis of follicular keratinocytes in this process has not yet been fully established..$^{50,51}$

The diameter of the follicles is directly determined by the size of the dermal papilla. ${ }^{52}$ Therefore, the miniaturization process is due to the decrease in the volume of the papillae. As the hair keeps the same thickness from the tip to the proximal portion, it is concluded that no thinning occurs during the anagen phase. Thus, it is understood that miniaturization occurs sometime between the catagen phase and the formation of the new hair. ${ }^{53,54}$ The factors that directly lead to a decrease in volume of the papillae are not known and should become primary targets in the developing of FPHL treatments and prevention strategies.

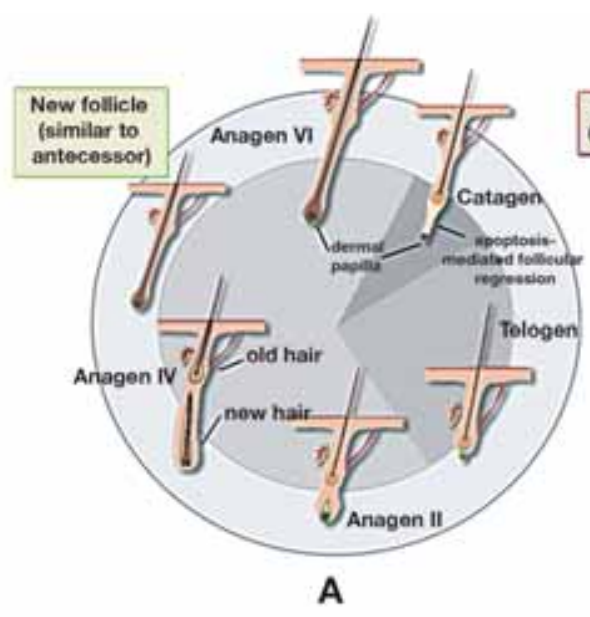

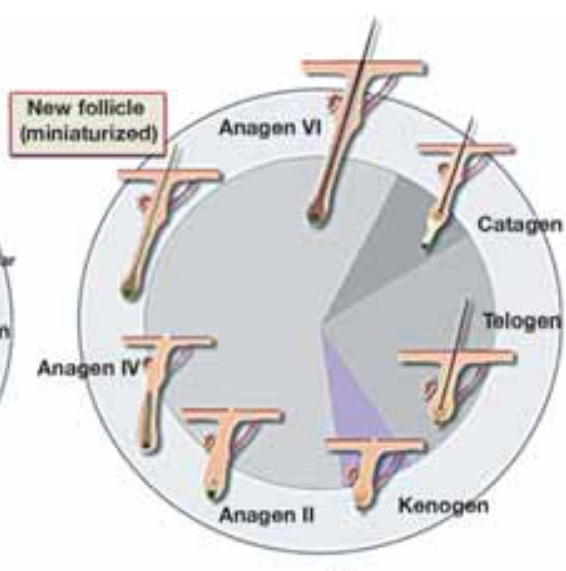

B
FiguRE 2:

Representative schemes of the hair cycle. A - Normal cycle of the follicle. B - Alterations occurring in baldness: shortening of the anagen phase, increase in the latency period (kenogen phase) and hair follicle minituarization. These alterations may occur together or individually both in FPHL and MPA. 
The miniaturized hair is very similar to vellus hair, but is not a true vellus hair. Although the hair is thin, it has a developed piloerector muscle, unlike the vellus hair, which has no or absent muscle.

A possible mechanism of follicle miniaturization is the decrease in the number of papilla cells due to apoptosis. ${ }^{55}$ Although apoptosis can be induced in the papilla fibroblasts in experimental situations, the papilla is the only component of the follicle which permanently expresses high levels of the antiapoptotic protein bcl-2, which in theory confers resistance against proapoptotic stimuli.50,51,55,56 The failure of antiapoptotic mechanisms should be investigated as a key element in the pathophysiology of FPHL.

Despite the importance of hormonal factors in the development of baldness, the action mechanisms through which they lead to shortening of the anagen phase and the miniaturization of the follicles have not yet been elucidated.

\section{HORMONAL FACTORS}

The dependence on androgens for the development of baldness in men was observed by Hippocrates (400 BC) and established by Hamilton in 1942. It was observed that eunuchs and men castrated before puberty did not develop baldness. However, the administration of testosterone $(\mathrm{T})$ induced alopecia in individuals with a family history of baldness. ${ }^{8}$ These observations together indicate that $\mathrm{T}$, or one of its metabolites, were involved in the development of MPA in individuals with genetic predisposition.

Androgens spread through the cytoplasmic membrane and connect themselves to specific intracellular receptors. This complex hormonereceptor promotes the transcription of genes that are primarily responsible for its tissue actions. ${ }^{57}$

The observation that men with a genetic deficiency of type-2 $5 \alpha$-reductase $(5 \alpha \mathrm{R})$ did not develop baldness suggested that dihydrotestosterone (DHT) was the main androgen involved in the development of MPA. ${ }^{58}$

$5 \alpha \mathrm{R}$ is an enzyme that converts $\mathrm{T}$ in DHT metabolite. There are two types of $5 \alpha \mathrm{R}$ : type 1 and type 2 . Type- $15 \alpha \mathrm{R}$ is present in sebaceous glands, and type-2 $5 \alpha \mathrm{R}$ is present in the genitourinary tract and in the hair follicles. ${ }^{59}$

The miniaturization of the hair follicle caused by androgens occurs primarily due to the action of DHT, which has five times greater affinity for the androgen receptor (AR) than testosterone. ${ }^{59}$ The androgen linked to the AR leads to the transcription of the genes responsible for its biological action on the target cells (Figure 3).

In addition, DHT may interfere with the follicular cycle by interacting with the Wnt signaling

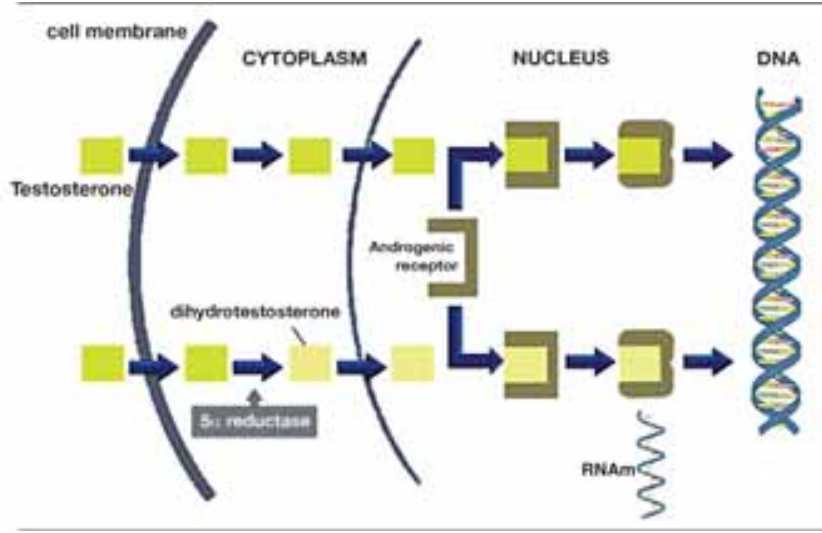

FIGURE 3: Representative scheme of the cellular action of androgens. Testosterone (T) enters the cell and is converted by the $5 \alpha$-reductase enzyme into dihydrotestosterone (DHT). Both T and DHT link themselves to the androgen receptor to promote alterations in cell DNA transcription

A dapted from Randall, $2008^{57}$

pathway. The Wnt pathway induces dermal papilla cells to maintain the anagen phase. ${ }^{45}$ The addition of DHT mediated by Wnt3a suppressed the growth of keratinocytes in culture with cells derived from the dermal papilla of the patient with baldness. ${ }^{60}$ The interplay of these pathways might be an important target for the treatment of baldness. A recent phase I clinical trial showed improvements in hair density and thickness in men with MPA through the infiltration of a complex containing Wnt activity. ${ }^{61}$

Despite the fact that the evidence indicating that androgens participate in baldness has emerged from studies in men, androgens were also assumed to play such role in female baldness, due to the idea that, in spite of the clinical differences, male and female baldness are the same entity.

Blocking of type- $25 \alpha \mathrm{R}$ proved effective in the treatment of MPA, confirming the importance of DHT in the pathophysiology of the disease. However, finasteride and dutasteride (even at higher doses) showed less consistent results in the treatment of FPHL. ${ }^{62-68}$

Aromatase is an enzyme that converts androstenedione to estrone and testosterone to estradiol, exerting an antiandrogenic action. In 1997, in a study by Sawaya involving 12 men and 12 women with baldness, the aromatase levels of the follicles of the frontal region of women with FPHL were half as high as those of the occipital region. When compared with the follicles of the frontal region of men showed, these levels were six times greater. ${ }^{69}$ These data suggest that aromatase may exert a protective action against baldness by converting androgens to estrogens. 


\section{MICROINFAMATION}

In baldness, the miniaturization process may be accompanied by a mild to moderate lymphohistiocytic inflammatory infiltrate in the peri-infundibular region. To term microinflamation has been used in order to differentiate it from the inflammation that occurs in scarring alopecia..$^{70,71}$

The frequency of this process is variable. In 1993, Whiting evaluated the presence of inflammatory infiltrate in 106 men with MPA and 22 controls (13 men and 9 women). Mild inflammatory infiltrate was found in $30 \%$ of cases and controls. However, moderate inflammatory infiltrate was found in 36\% of cases compared to only $9.1 \%$ of controls. ${ }^{72}$

The fact that the inflammatory process occurs in the upper part of the follicle suggests that the causal factor may affect this region. External factors such as ultraviolet radiation, environmental pollutants, inhabitants of the skin microbiota and follicle (such as Propionibacterium sp.; Staphylococcus sp.; M al assezia sp.), among others, could be involved in the induction of the microinflamation process. ${ }^{70}$

The real meaning of this inflammatory process for development of FPHL, as well as its possible relation to the miniaturization process and the hormonal elements involved in FPHL have not yet been established.

\section{GENETICS}

Patients with FPHL often report family members affected by the disease (40-54\%), especially in cases with early clinical presentation ( $<40$ years). ${ }^{21}$ A comparative study which assessed baldness in male twins found a twice higher agreement level in monozygotic twins than in dizygotic twins. ${ }^{73}$

Family segregation is not yet fully understood, however, the high prevalence of FPHL and the fact that FPHL manifests with varying degrees of intensity and has its onset at different ages, suggest a polygenic pattern with incomplete penetrance. ${ }^{74,75}$ In addition, family influence in the development of baldness may vary between men and women and according to the form of presentation (classical or diffuse).$^{76}$

Despite the importance of DHT in the development of MPA, no correlation was found between the SRD5A1 and SRD5A2 genes (responsible for the production of type 1 and type $25 \alpha$-reductase enzymes) and the development of baldness. ${ }^{77}$

The strongest evidence of genetic involvement in the development of baldness comes from studies involving the AR gene in men. A single nucleotide polymorphism in the first exon, known as STUL was associated with baldness. Although this change is found in $98 \%$ of men with premature baldness and in $92 \%$ of men with late baldness, it was also found in
$77 \%$ of men without baldness. ${ }^{78-80}$

These elements suggest that other changes are necessary for development of MPA, which supports the hypothesis of a polygenic origin and epigenetic control of this entity, such as hormonal changes, medications, and environmental stimuli.

The number of CAG repeats in the first exon of the AR gene varies among individuals. An inverse relationship between the number of CAG repeats in its amino-terminal portion and the activation of AR was observed. This implies that individuals with shorter repetitions are at increased risk of baldness. ${ }^{75}$

However, as the AR gene is located on chromosome $X$, this does not justify the agreement of phenotypes of fathers and sons. Thus, there is either a direct maternal transmission or a polygenic inheritance (autosomal). Another hypothesis is that, in addition to this gene, other environmental elements are involved in the development of baldness.

There is less evidence of the participation of the AR gene in the pathophysiology of FPHL than in that of MPA. No relationship has been found between the presence of the StuI restriction fragment and FPHL. ${ }^{81}$ However, just as in men, the number of CAG repeats in the first exon of the AR gene was inversely correlated with FPHL. ${ }^{82,83}$ This observation allowed the development of genetic testing, in which the detection of a small number of CAG repeats is associated with an increased risk of development of FPHL, whereas a larger number of repeats is associated with a lower risk (http:/ / www.hairdx.com).

In women with FPHL (especially in younger women), nonfunctioning single nucleotide polymorphism (rs4646) was identified in the gene that encodes aromatase (CYP19A1) ${ }^{84}$

A meta-analysis of seven genome-wide association studies identified six susceptibility loci associated with MPA: 1p36.22, 2q37.3, 7p21.1, 7q11.22, 17q21.31 and 18q21.1. ${ }^{85}$ However, a study conducted by Redler in 2013, involving 405 women with baldness and 469 controls found no association between these loci and FPHL. ${ }^{86}$

In a subsequent study, four new loci associated with MPA (2q35, 3q25.1, 5q33.3 and 12p12.1) were not associated with FPHL. ${ }^{87,88}$ These data together suggest that MPA and FPHL have different etiopathogenic factors.

Besides genetics, external factors may also be important for the development of FPHL. A US study conducted in 2012 with 98 female identical twins, raised several environmental factors possibly related to FPHL. These included: testosterone levels, psychological stress, hypertension, diabetes mellitus, smoking, multiple marriages, lack of photoprotection, higher income and little physical activity. ${ }^{89}$ However, 
the actual role of these factors in the causal model of FPHL still need be determined.

\section{QNICAL PRESENTATION ANDQASSIFCATION}

Reduction in hair thickness and density leads to a reduction in the overall hair volume (average hair thickness $\mathrm{x}$ number of hairs). ${ }^{19,78}$

This phenomenon can be noticed by the patient in various ways. By dividing the hair in the middle, the dividing line becomes more evident (line sign); and when the hair is tied together (ponytail), the ponytail holder becomes loose or it is necessary to pull the hair more often through the used rubber band. ${ }^{17} \mathrm{As}$ the clinical picture evolves, the scalp becomes more visible and may be fully visible in more advanced cases.

Clinically, FPHL can manifest in three ways: ${ }^{90}$

1.Diffuse thinning of the upper biparietal and vertex region preserving the anterior hair implantation line. This pattern can be classified using two scales. That of Ludwig, ${ }^{7}$ which divides it into three degrees, from a mild light thinning in the first degree to the complete absence of hairs in the affected area in the third degree (Figure 4). Although widely used, this scale has limitations because does not make it possible to classify intermediate stages more precisely. Moreover, it is not a good tool for therapeutic evaluation, as treatment - even follicular transplant - can hardly go back a full stage in the classification. Sinclair's classification is similar, but the disease is subdivided into four levels of intensity based on the normal scalp, which makes it more adjustable to the reality of each patient (Figure 5). ${ }^{91}$

1.Thinning of the upper bitemporal region and vertex with frontal accentuation (Christmas tree pattern). In this pattern which was described by Olsen in $1999,{ }^{92,93}$ in addition to the diffuse thinning process, there is an accentuation in the central line, opening up into a triangle with its base at the anterior hair implantation line (Figure 6).

1.Thinning with bitemporal recess (Figure 7). This is said to be the classical clinical presentation. It was proposed by Hamilton in 1951 and modified by Norwood in 1975.9,94 This system is mainly used for the classification of male baldness, however, this pattern can also rarely occur in women.

In 2011, a new classification known as BASP (basic and speficic) was developed by Lee. Lee's aim was to develop a unified scale, which was easy to remember and apply and could be used in various types of baldness presentation in both men and women. ${ }^{95-97}$

The basic forms are represented by the shape of the anterior hair implantation line (L, M, C and U). Specific features relate to the hair density in different areas (frontal and vertex). The final classification depends on the combination of basic and specific forms (Figure 8)..$^{97}$

On physical examination, the pull test (Sabouraud's sign) may reveal an increase in the release of telogen hairs. The amount of hairs that come off depends on the amount of hairs pulled. Considering that 10 to $20 \%$ of hairs are in the telogen phase and many of them are still firmly adhered to the epithelial bag, it is expected that up to $10 \%$ of the hairs pulled may come off. ${ }^{17}$

When the test is positive in FPHL, it is restricted to the areas affected by the disease. A diffusely positive test indicates telogen effluvium or diffuse alopecia areata. ${ }^{96}$ The presence of telogen hairs smaller than three centimeters represents the telogen phase of the miniaturized follicles and are strongly suggestive of the diagnosis of FPHL. ${ }^{15}$ The test shows great interexaminer variability and lack of standardization. A recent hair wash with detachment of telogen hairs can influence the test results.

Usually, FPHL is not accompanied by systemic symptoms or clinical findings extending beyond the scalp.

Clinically, the initial forms of FPHL or diffuse thinning can make diagnosis difficult due to other forms of non-scarring diffuse alopecia such as chronic telogen effluvium, senile alopecia, diffuse alopecia areata, alopecia areata incognita, loose anagen hair syndrome and syphilitic alopecia. ${ }^{98-109}$

The overlap between diagnoses occurs with some frequency, eventually revealing clinical pictures of initial FPHL. The use of additional semiotic techniques such as trichogram, dermoscopy, TrichoScan ${ }^{\circledR}$ and histopathological examination helps the diagnosis of FPHL in such cases.

\section{TRIOHOGRAM}

Trichogram is a technique in which a sample of hairs - generally containing between 50 and 100 hairs - removed from the scalp is analyzed with a light microscope.

This test allows to assess the number of hairs in each phase of the cycle (anagen, catagen or telogen) and is especially indicated in case of suspicion of anagen effluvium or loose anagen syndrome. It should only be performed by trained dermatologists who frequently perform this test. ${ }^{16,90}$

\section{DERMOSCOPY}

Dermoscopy is noninvasive test. It is easy to perform and can contribute to the diagnosis of FPHL, especially in the early stages of the disease. ${ }^{110-112}$

The main dermoscopic finding is the diversity of the thickness of the hairs with an increased number 


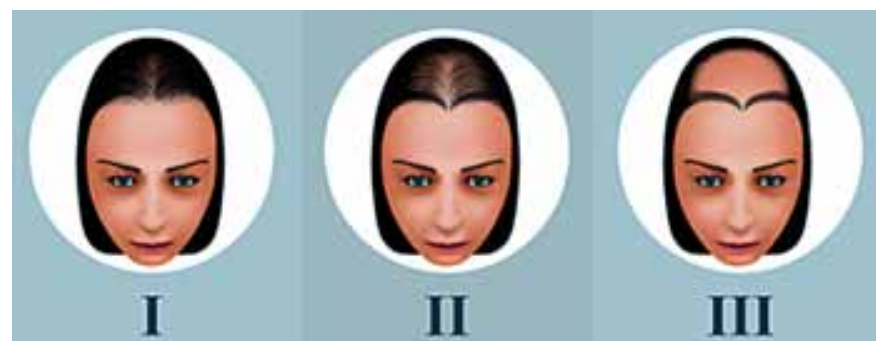

Figure 4: Ludwig's classification. First proposed classification of MPA. MPA was divided into three intensity degrees.

A dapted from Ludwig, $1977^{7}$

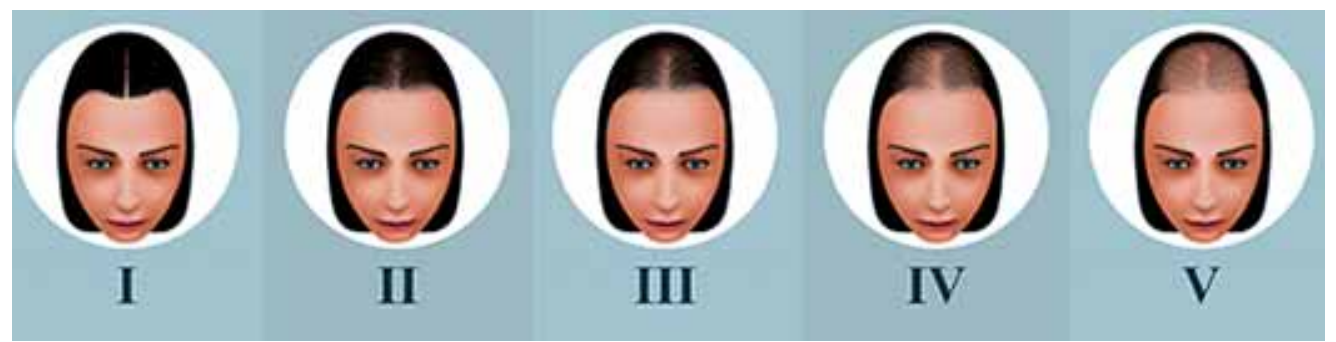

FIGURE 5: Sinclair's classification. MPA is divided into four levels of intensity based on the normal scalp to the left.

A dapted from Sinclair et al, $2005^{91}$

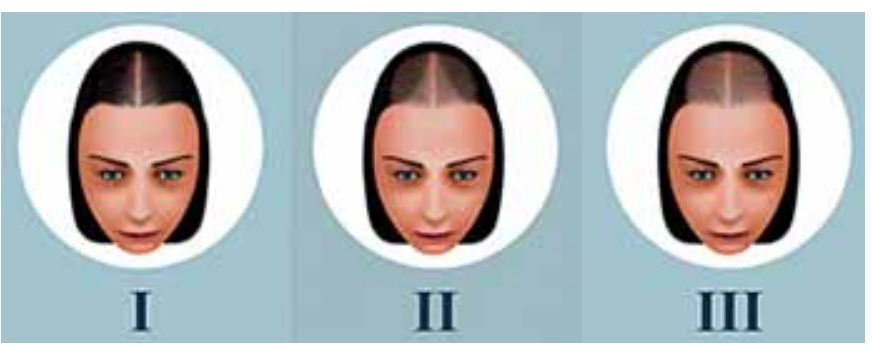

of miniaturized hairs, especially in the frontoparietal region (Figure 9). ${ }^{110}$ In 2012, in a study involving 34 patients with FPHL, these changes were found in all subjects. ${ }^{113}$ The single observation of more than $10 \%$ of fine hairs is strongly suggestive of the diagnosis. ${ }^{114}$

A decrease in the number of hairs per follicular unit is another important element. Typically, most hairs emerge from the follicular ostium in groups of 2 to 4 . In PFA, the hairs emerge alone or in groups of 2 (Figure 9).

The peripilar sign, a light brown area, slightly atrophic around the follicle, usually occurs in the early stages of FPHL. This sign shows correlation with the inflammatory infiltrate seen in the anatomopathological examination. ${ }^{115}$

Yellow dots may be seen in more advanced cases, probably as a result of sebum and keratin buildup in dilated follicles. ${ }^{114}$ With increasing thinning of the hairs, there is greater penetration of ultraviolet radiation into the scalp and alterations typical of photoaging, such as the honeycomb pigmented network, may occur.

These signs, when evaluated together, allow
FIGURE 6: Olsen's classification. Other than diffuse thinning, there is also a frontal accentuation opening towards the anterior hair implantation line, creating a "Christmas tree" pattern.

A dapted from O Isen $2002^{10}$ and OIsen $2003^{93}$ the early diagnosis of FPHL, before the occurrence of significant reduction in hair volume. In 2009, Rakowska standardized some criteria for the diagnosis of FPHL based on dermoscopic findings (Chart 2). ${ }^{114}$

\section{TRICHOSCAN®}

TrichosScan $^{\circledast}$ is a system that combines epiluminescence microscopy and automated digital image analysis. It allows the estimation of the number and density of hairs, of the percentage of terminal and vellus hairs, and by mathematical approximation, of the percentage of hairs in the anagen and telogen phases. ${ }^{116,117}$

To perform the test, a small area of the scalp (aproximately $1 \mathrm{~cm}^{2}$ ) is shaved and evaluated after 48 to 72 hours The software performs an automatic analysis of the image captured by the camera. The total number of hairs in the area, the hair density per $\mathrm{cm}^{2}$, and the percentage of terminal hairs (thickness greater than $40 \mu \mathrm{m}$ ) and vellus hairs (thickness smaller than $40 \mu \mathrm{m})$ is determined.

Anagen hairs, unlike telogen hairs, undergo a continuous growth process. As the images are 


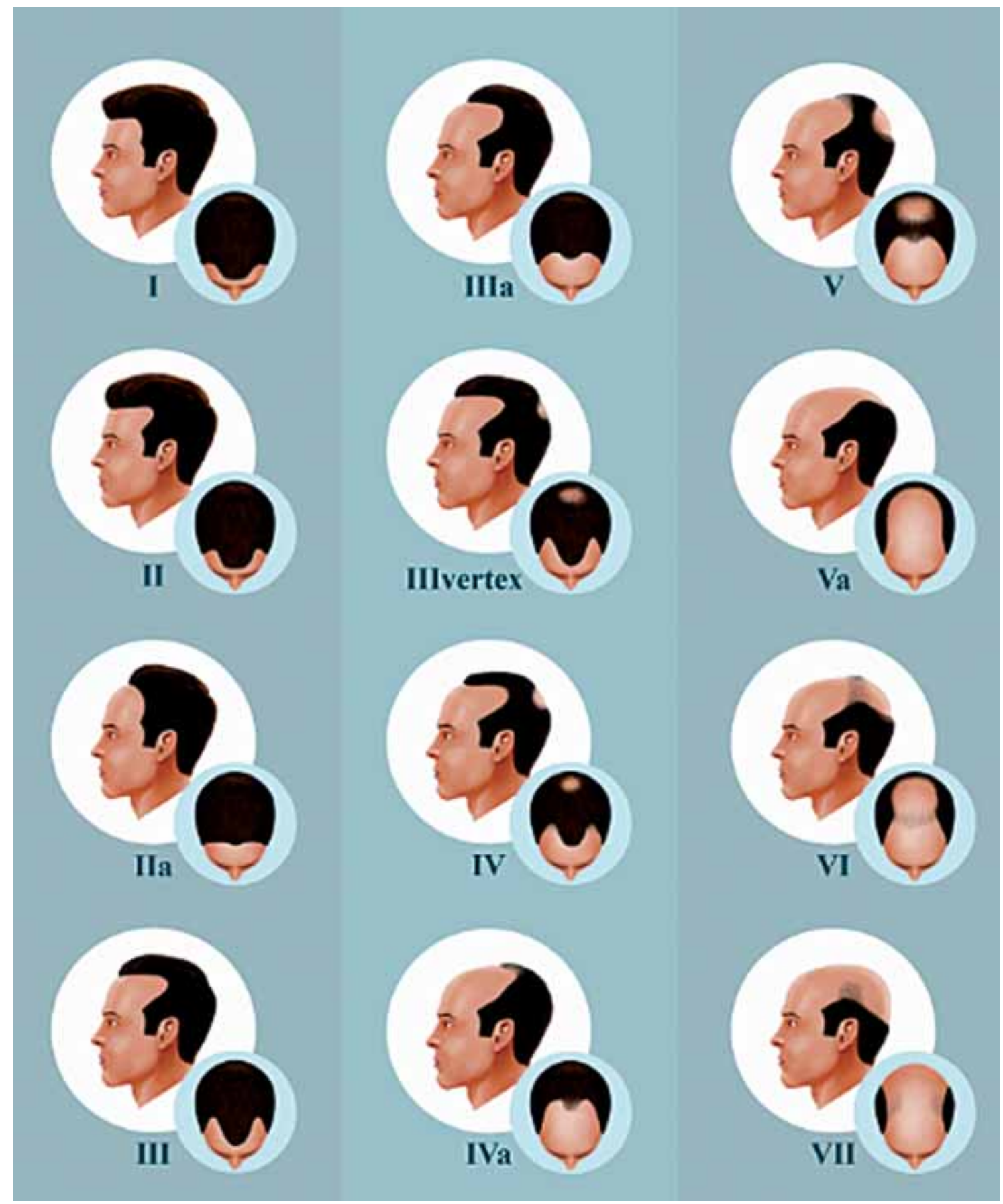

Figure 7:

Hamilton-

Nordwood's

classification.

Created for the

classification of

MPA.

This pattern rarely

affects women

A dapted from

N orwood, $1975^{\circ}$

analyzed 72 hours after shaving, the length of the hair allows to differentiate between those hairs that grew and those that did not. Those hairs that grew are classified as anagen and those who did not are classified as telogen.

TrichosScan ${ }^{\circledR}$ can be used as a diagnostic aid tool and for monitoring patients in treatment. To ensure reproducibility in subsequentassessments, it is advisable to tattoo the area to be assessed.

\section{LABORATORY ALTERATIONS}

FPHL is not associated with characteristic laboratory alterations. The investigation of the causes of telogen effluvium can benefit the therapeutic response in patients with concomitant conditions.

An association between possible changes in ferritin levels and FPHL is controversial. Some studies have demonstrated lower ferritin levels in patients with FPHL when compared to controls, and improved 


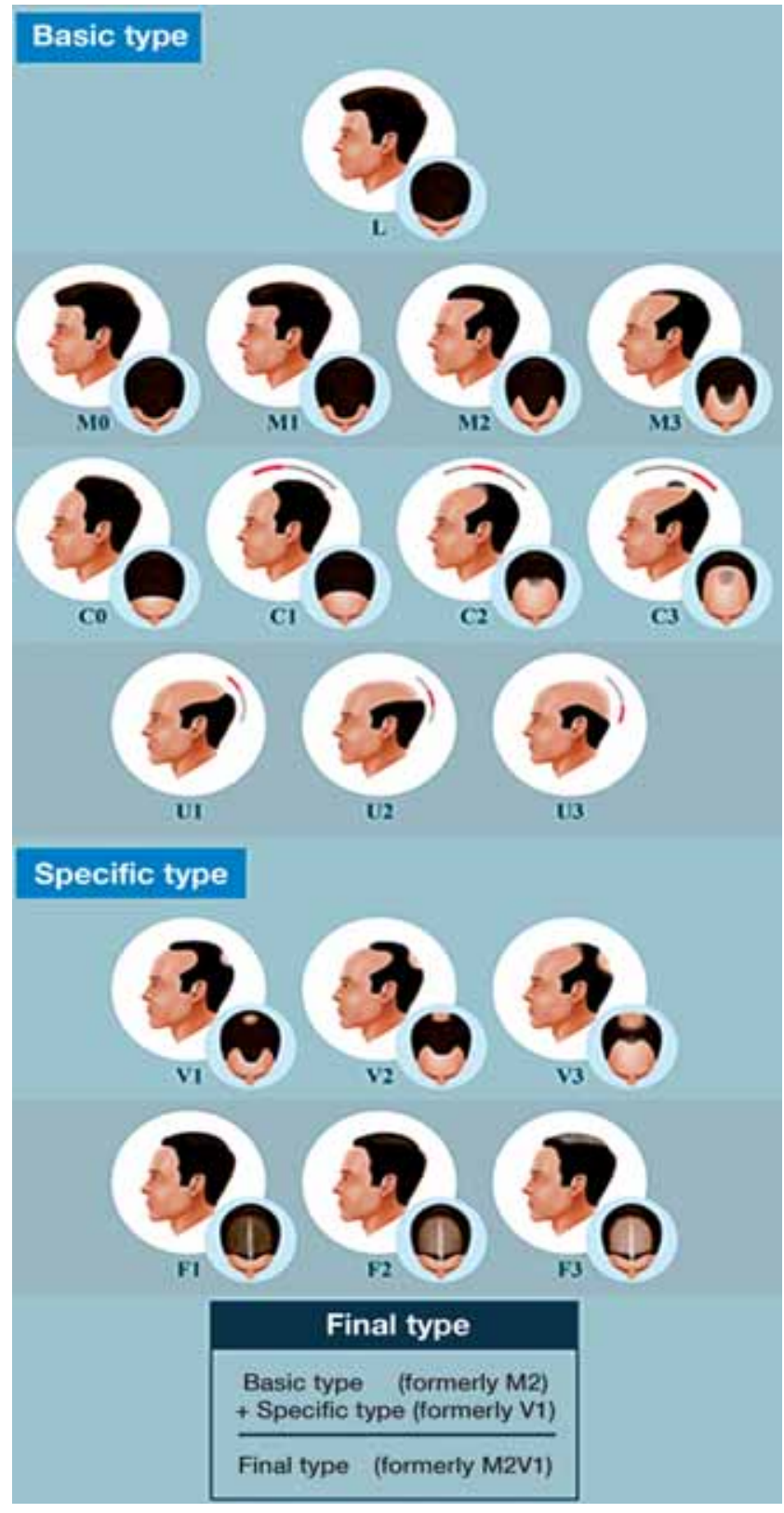

Figure 8: The basic type (BA) is defined by the shape of the anterior hair implantation line. There are 4 types and they are designated by letters. Type $\mathrm{L}$, there is no hair loss in the frontal hair implantation line, linear pattern Type $\mathrm{M}$, the bilateral frontotemporal recess is more prominent than the central recess. It has the shape of the letter $\mathrm{M}$. Type $\mathrm{C}$, the central recess is more prominent than the frontotemporal recess. It has the shape od the letter $\mathrm{C}$. Types $\mathrm{M}$ and $\mathrm{C}$ are subdivided into 4 groups, according to the intensity. Type $\mathrm{U}$, the frontal line is behind the vertex. It has the shape of a horseshoe or of the letter $U$. Type $U$ is subdivided into 3 groups, according to the position of the hair implantation line between the vertex and the occipital protuberance. The specific type (SP) represents the capillary density in certain areas. Type F (frontal), decreased hair density across the top area of the scalp, except the anterior line. Type $\mathrm{V}$ is the rarefaction in the vertex region. Specific types are subdivided into 3 groups, according to the intensity. When the patient presents both types ( $\mathrm{F}$ and $\mathrm{V}$ ), both types should be described. The final type is decided by the combination of the assigned basic and specific types.

A dapted from Lee et al, $2011^{95}$
Chart 2: Dermoscopic criteria for the diagnosis of FPHL. Two major criteria or one major criterium and two minor criterium indicate the diagnosis with $98 \%$ specificity

Major criteria 1 - More than 4 yellow in 4 areas of the frontal region (70x magnification)

2 - Decreased average thickness of hairs in the frontal region when compared with the occipital region (evaluation of at least 50 hairs from each area)

3 - More than $10 \%$ of fine hairs $(<0,03$ $\mathrm{mm}$ ) in the frontal region

Minor criteria 1 - Ratio between the number of isolated hairs per follicular unit of the frontal area and the number of isolated hairs per follicular unit of the occipital area is $>2: 1$

2 - Ratio between the number of fine hairs in the frontal area and the number of fine hairs in the occipital area is $>1,5: 1$

3 - Ratio between the number of hyperpigmented follicles in the frontal area and the number of hyperpigmented follicles in the occipital area is $>3: 1$

response to antiandrogen therapy in patients with ferritin levels greater than $40 \mu \mathrm{g} / 1{ }^{118,119}$

However, a review conducted by Trost and colleagues in 2006 concluded that there is no evidence for routine determination of ferritin levels in hair loss research, as well as there is no evidence for iron supplementation in patients without anemia. The decision to perform or not perform a laboratory research and supplementation should be taken individually. ${ }^{120}$

Trost also states that, despite the lack of evidence, he does perform routine laboratory tests and treats iron deficient patients irrespective of whether or not they have anemia. He justifies his conduct by saying that he believes that patients show a better therapeutic response when their serum ferritin levels are above 20 $\mu \mathrm{g} / \mathrm{ml}{ }^{120}$

Most women with PFA do not have hyperandrogenism. The presence of other signs and symptoms that are indicative of hyperandrogenism, such as changes in the menstrual cycle, infertility, clitoral hypertrophy, changes in libido, hirsutism, acne, oily skin and changes in voice timbre should be 


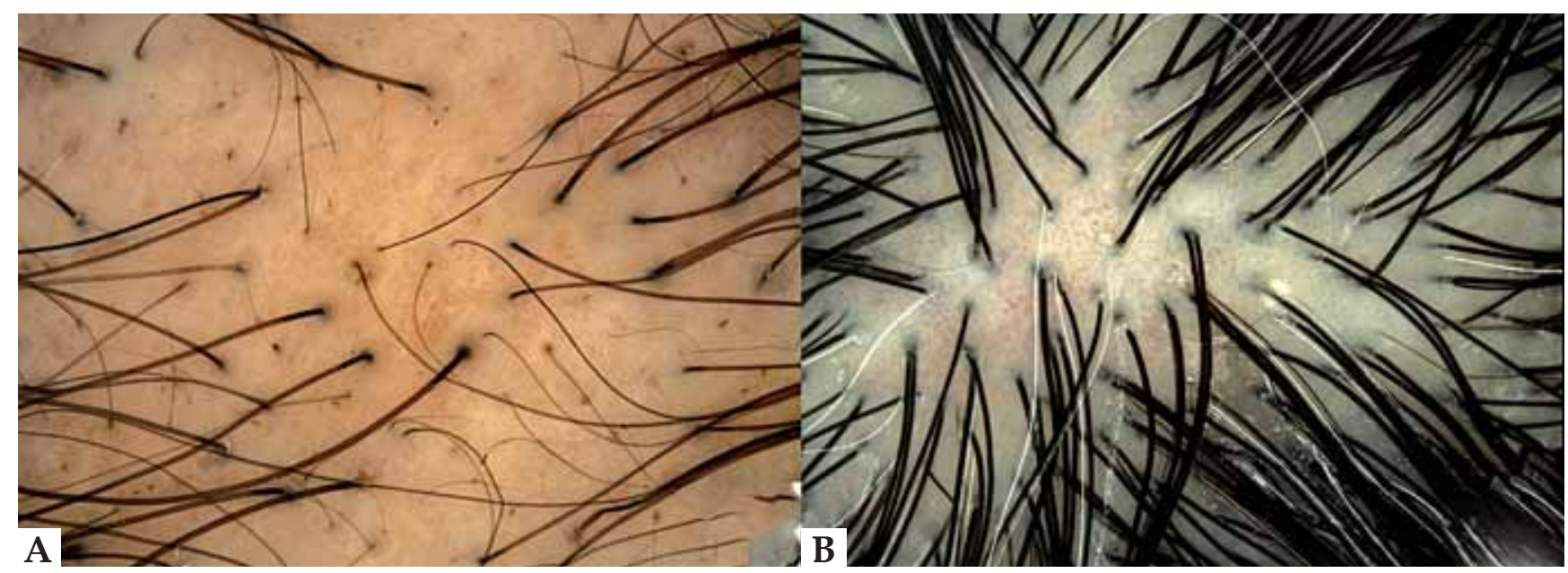

FIGURE 9: Dermoscopy of the scalp. A) FPHL. There is great variability in the thickness of the hair shaft, hairs emerging individually from the follicular ostium, reduced follicle density (late finding) and incipient pigment network between follicles. B) Normal. Uniformity in the thickness of the hairs and several hairs emerging from the same ostium

clinically evaluated and constitute a warning sign. ${ }^{121}$

The European Consensus held in 2011 recommends free androgen index (FAI) and prolactin dosage as screening tests. The FAI is the relationship between total testosterone and sex hormone-binding glubulin (SHBG) [Total Testosterone (nmol/L)/SHBG $(\mathrm{nmol} / \mathrm{L}) \times$ 100]. Depending on the results and on the clinical context, a complementary endocrinologic evaluation can be performed. FAI of 5 or greater is indicative of polycystic ovary syndrome. The use of hormonal contraceptives causes alterations in SHBG levels. Therefore, laboratory tests should only be carried out after a hormonal contraceptive pause of at least 2 months. ${ }^{90}$

Likewise, TSH levels should be controlled, as thyroid dysfunctions may contribute to the effluvium associated with FPHL. ${ }^{122}$

The importance of vitamin $\mathrm{D}$, in addition to calcium metabolism, has been widely discussed in recent years. A recent study involving 80 female patients with telogen effluvium or FPHL and 40 controls showed lower levels of vitamin D in cases than in controls. ${ }^{123}$ However, its role in the hair cycle and in the development of alopecia has yet to be established. ${ }^{124,125}$

\section{ANATOMOPATHOLOGCOHANGES}

Most of the times, the diagnosis of FPHL can only be established based on clinical elements. Very early cases, atypical presentations and possible coexistence with other types of alopecia may require the performance of a histopathological examination for its definition.

The traditional analysis of longitudinal sections allows visualization of the entire follicle, which is essential for the assessment of alopecias associated with lichenoid infiltrate, interface and subcutaneous alterations. ${ }^{71}$ However, longitudinal sections allow the assessment of only a small number of sample follicles, making it impossible to perform a quantitative analysis of the follicles, which is necessary for the diagnosis of FPHL.

The analysis of the follicles using transverse sections standardized by Whiting in 1993, allows the benchmarking among all the follicles of the sample and is a standard method for the histological evaluation of patients with suspicion of FPHL. ${ }^{72}$

Therefore, ideally a two-point biopsy (4$\mathrm{mm}$ punch) should be performed to allow both the transverse and the horizontal sections. ${ }^{71}$

The main alteration found in the horizontal section is the increase in the proportion of miniaturized hairs when compared to terminal hairs (Figure 10).

Conceptually, terminal hairs have a diameter greater than $0.03 \mathrm{~mm}$ and are thicker than their inner root sheath. Vellus hairs and miniaturized hairs have a diameter smaller than $0.03 \mathrm{~mm}$ and are thinner than the inner root sheath. The differentiation between primary vellus hair and miniaturized hairs can be made by observing the outer root sheath (which is more structured) and the piloerector muscle (which is more developed) of miniaturized hairs.

There is a reduction in the anagen/telogen ratio and, in advanced cases, a reduction in the follicular density. In addition, a discreet perifollicular lymphohistiocytic inflammatory infiltrate and fibrosis, associated with a worse prognosis, may occur. ${ }^{72,126}$

In vertical sections, a band which is characteristic of the residual connective tissue can be seen in the depth of the dermis, under the miniaturized follicles. ${ }^{106}$ 


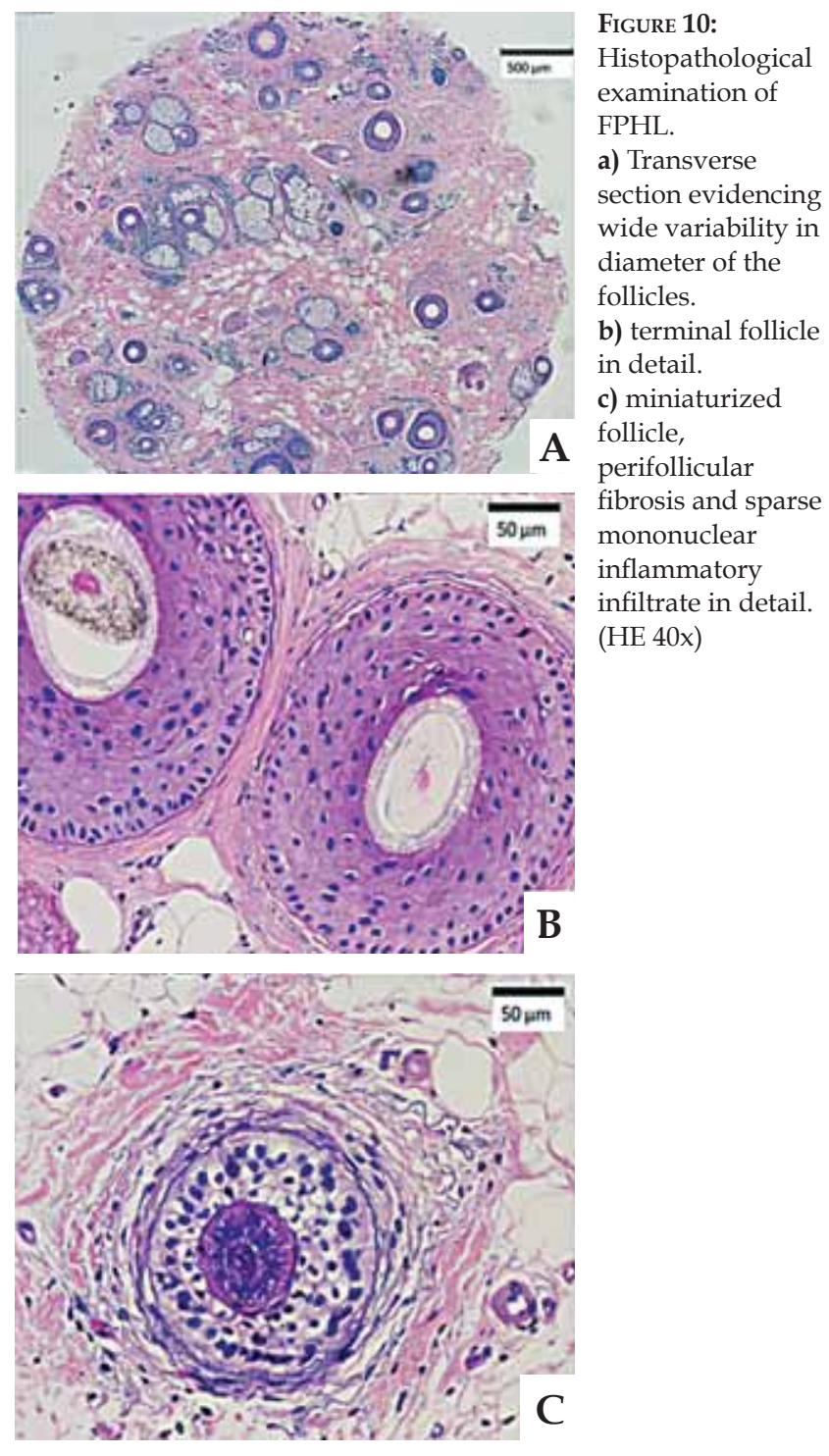

\section{QUAUTYOFUFE}

Although the hairs do not exhibit a vital biological function, they are of marked importance for appearance, self-esteem and social identity function. ${ }^{13}$

The severity of alopecia, established by the dermatologist through classification systems, does not predict the perception of the patient about the severity of his/her case or its impact on his/her quality of life. ${ }^{12}$ Therefore, dermatologists should be aware of the emotional components and use specific tools to assess the impact of FPHL patients' quality of life.

For women, having healthy hair involves feelings of self-esteem, mutability and social interaction. A study conducted in Brazil in 2012, the fear of losing all the hairs was as great as the fear of developing a myocardial infarction. ${ }^{127}$

Despite the existence of several generic questionnaires to assess quality of life, they do not always properly cover all areas of specific diseases. In 2000, Dolte and colleagues developed and validated a specific questionnaire to assess quality of life in patients with FPHL: the "Women's Androgenetic Alopecia Quality of Life Questionnaire" (WAAQOL). ${ }^{128}$

Although the questionnaire has demonstrated excellent psychometric properties, the WAA-QOL is still little used in clinical research, and has not yet been translated and culturally adapted into Brazilian Portuguese. However, it is an important tool for assessing both the individual impact of FPHL in patients' quality of life and treatment response in clinical trials.

\section{FNALCONSIDERATIONS}

Despite the high prevalence of FPHL, its management still imposes several difficulties to dermatologists' clinical practice.

Its nomenclature and diagnostic definition still generate conflicts between authors of different publications. Genetic elements are not completely known. The actual participation of hormones is still unclear. $^{5}$

Although the microscopic alterations between FPHL and MPA are identical, when considering the diversity of clinical presentations and responses to treatment, we cannot be sure that they are the same entity with different presentations between the sexes. ${ }^{5}$

Although treatment is not considered part of the scope of this text, it should be noted that the therapeutic response of FPHL is variable and less expressive than that of MPA. Even with use of antiandrogens, combined oral contraceptives, topical minoxidil and low power laser, there is no full recovery, and sometimes recovery is not even clinically noticeable in patients. ${ }^{129,130}$ Follicular transplantation has certain limitations with regard to the availability of donor areas in diffuse cases and the augmentation of capillary volume in the transplanted area. Moreover, prolonged medical treatment is still necessary. ${ }^{131-133}$

The identification of vulnerable patients associated with the diagnosis of early forms of FPHL, as well as the early introduction of therapy may promote better clinical results than those achieved in more advanced cases or even stop the progression of the disease.

It should be noted that there is still low accuracy in FPHL detection though clinical photographs. Patients' reports, dermoscopy and TrichoScan ${ }^{\circledR}$ should be used for the objective and longitudinal evaluation of alopecia in therapeutic clinical trials associated with FPHL. Improvement in semiotic techniques will allow a more accurate diagnosis and better detection 
of outcomes in clinical trials. ${ }^{134}$

It is essential to advance in the knowledge of the pathophysiology of FPHL in order to develop new and more effective therapies for the prevention and reversing of the disease process. This includes detailed investigation of other potential elements (other than genetic and hormonal elements) involved in its pathogenesis. ${ }^{37}$

More than describing in detail the minutiae of the hair cycle, the elucidation of the epidemiology, genetics and pathophysiology of FPHL are a hope for improving the quality of life of patients affected by this disease. $\square$

\section{ACKNOWLDGMENTS}

We thank Prof. Mayra Ianhez for critically reviewing this manuscript and $\mathrm{PhD}$ student Carla Müller Ramos for her key role in the development of the illustrations.

\section{REFERENCES}

1. Jmrezende.com.br [Internet]. Rezende JM. Linguagem médica: Alopécia alopecia. 2011. [acesso 11 nov 2013]. Disponível em: http://www.jmrezende. com.br/alopecia.htm.

2. Academia.org.br [Internet]. Busca no vocabulário. Academia Brasileira de Letras, 2009. [acesso 11 nov 2013]. Disponível em: http://www.academia.org.br/abl/cgi/ cgilua.exe/sys/start.htm?sid=23.

3. Decs.bvs.br [Internet]. Descritores em ciências da saúde. Biblioteca Virtual em Saúde, 2013. [acesso 11 nov 2013]. Disponível em: http://decs.bvs.br/cgi-bin/ wxis1660.exe/decsserver/.

4. Plenck JJ. Doctrina de Morbis Cutaneis. Qua hi morbi in suas classes, genera et species redingtur. Vienna: Van Overbeke; 1776.

5. Sinclair R. Winding the clock back on female androgenetic alopecia. Br J Dermatol. 2012;166:1157-8.

6. Sulzberger MB, Witten VH, Kopf AW. Diffuse alopecia in women. Its unexplained apparent increase in incidence. Arch Dermatol. 1960;81:556-60.

7. Ludwig E. Classification of the types of androgenetic alopecia (common baldness) occurring in the female sex. Br J Dermatol. 1977:97:247-54.

8. Hamilton JB. Male hormone stimulation is prerequisite and an incitant in common baldness. Am J Anat. 1942;71:451-80

9. Norwood OT. Male pattern baldness: classification and incidence. South Med J. 1975;68:1359-65.

10. Olsen EA. Female pattern hair loss. J Am Acad Dermatol. 2002;45:S70-80

11. Shapiro J. Clinical practice. Hair loss in women. N Engl J Med. 2007;357:1620-30.

12. Reid EE1, Haley AC, Borovicka JH, Rademaker A, West DP, Colavincenzo M, et al. Clinical severity does not reliably predict quality of life in women with alopecia areata, telogen effluvium, or androgenic alopecia. J Am Acad Dermatol. 2012;66:556-102.

13. Schmitt JV, Ribeiro CF, Souza FH, Siqueira EB, Bebber FR. Hair loss perception and symptoms of depression in female outpatients attending a general dermatology clinic. An Bras Dermatol. 2012;87:412-7.

14. Sociedade Brasileira de Dermatologia SBD. Perfil nosológico das consultas dermatológicas no Brasil. An Bras Dermatol 2006;81:545-54.

15. Tosti A, Piraccini BM. Androgenetic alopecia. In: Tosti A, Piraccini BM, editors. Diagnosis and treatment of hair disorders: An evidence based atlas London: Taylor and Francis; 2006. p.45-56.

16. Pereira JM. Propedêutica das doenças dos cabelos e do couro cabeludo. Rio de Janeiro: Atheneu; 2001.

17. Pereira JM. Alopecia Androgenética (Calvície) na Mulher. 2. São Paulo: Di Livros; 2007.

18. Norwood OT. Incidence of female androgenetic alopecia (female pattern alopecia) Dermatol Surg. 2001;27:53-4.

19. Birch MP, Messenger JF, Messenger AG. Hair density, hair diameter and the prevalence of female pattern hair loss. Br J Dermatol. 2001;144:297-304.

20. Gan DC, Sinclair RD. Prevalence of male and female pattern hair loss in Maryborough. J Investig Dermatol Symp Proc. 2005;10:184-9.

21. Paik JH, Yoon JB, Sim WY, Kim BS, Kim NI. The prevalence and types of androgenetic alopecia in Korean men and women. Br J Dermatol. 2001;145:95-9.

22. Wang TL, Zhou C, Shen YW, Wang XY, Ding XL, Tian S, et al. Prevalence of androgenetic alopecia in China: a community-based study in six cities. $\mathrm{Br} J$ Dermatol. 2010;162:843-7.

23. Su LH, Chen LS, Chen HH. Factors associated with female pattern hair loss and its prevalence in Taiwanese women: a community-based survey. J Am Acad Dermatol. 2013;69:556-77.

24. Lee AT, Zane LT. Dermatologic manifestations of polycystic ovary syndrome. Am J Clin Dermatol. 2007;8:201-19.
25. Cela E, Robertson C, Rush K, Kousta E, White DM, Wilson H, et al. Prevalence of polycystic ovaries in women with androgenic alopecia. Eur $\mathrm{J}$ Endocrinol. 2003; 149:439-42.

26. Tosti A, Pazzaglia M, Soli M, Rossi A, Rebora A, Atzori L, et al. Evaluation of sexual function with an international index of erectile function in subjects taking finasteride for androgenetic alopecia. Arch Dermatol. 2004;140:857-8

27. Kim BJ, Kim JY, Eun HC, Kwon OS, Kim MN, Ro BI. Androgenetic alopecia in adolescents: a report of 43 cases. J Dermatol. 2006;33:696-9.

28. Madnani N, Khan K, Chauhan P, Parmar G. Polycystic ovarian syndrome. Indian J Dermatol Venereol Leprol. 2013;79:310-21.

29. Dalamaga M, Papadavid E, Basios G, Vaggopoulos V, Rigopoulos D, Kassanos D, et al. Ovarian SAHA syndrome is associated with a more insulin-resistant profile and represents an independent risk factor for glucose abnormalities in women with polycystic ovary syndrome: A prospective controlled study. J Am Acad Dermatol. 2013;69:922-30.

30. Ding EL, Song Y, Manson JE, Hunter DJ, Lee CC, Rifai N, et al. Sex hormonebinding globulin and risk of type 2 diabetes in women and men. N Engl J Med. 2009;361:1152-63.

31. Arias-Santiago S, Gutiérrez-Salmerón MT, Buendía-Eisman A, Girón-Prieto MS, Naranjo-Sintes R. Sex hormone-binding globulin and risk of hyperglycemia in patients with androgenetic alopecia. J Am Acad Dermatol. 2011;65:48-53.

32. Yi SM, Son SW, Lee KG, Kim SH, Lee SK, Cho ER, et al. Gender-specific association of androgenetic alopecia with metabolic syndrome in a middle-aged Korean population. Br J Dermatol. 2012;167:306-13.

33. Abdel Fattah NS, Darwish YW. Androgenetic alopecia and insulin resistance: are they truly associated? Int J Dermatol. 2011;50:417-22.

34. Su LH, Chen LS, Lin SC, Chen HH. Association of androgenetic alopecia with mortality from diabetes mellitus and heart disease. JAMA Dermatol. 2013:149:601-6.

35. Mansouri P, Mortazavi M, Eslami M, Mazinani M. Androgenetic alopecia and coronary artery disease in women. Dermatol Online J. 2005;11:2.

36. Arias-Santiago S, Gutiérrez-Salmerón MT, Castellote-Caballero L, Buendía-Eisman A, Naranjo-Sintes R. Androgenetic alopecia and cardiovascular risk factors in men and women: a comparative study. J Am Acad Dermatol. 2010;63:420-9.

37. Messenger AG. Hair through the female life cycle. Br J Dermatol. 2011;165:2-6.

38. Paus R, Cotsarelis G. The biology of hair follicles. N Engl J Med. 1999;341:491-7.

39. Cotsarelis G, Millar SE. Towards a molecular understanding of hair loss and its treatment. Trends Mol Med. 2001;7:293-301.

40. Rebora A, Guarrera M. Kenogen. A new phase of the hair cycle? Dermatology. 2002;205:108-10.

41. Garza LA, Liu Y, Yang Z, Alagesan B, Lawson JA, Norberg SM, et al. Prostaglandin D2 inhibits hair growth and is elevated in bald scalp of men with androgenetic alopecia. Sci Transl Med. 2012;4:126ra34.

42. Trueb RM. Molecular mechanisms of androgenetic alopecia. Exp Gerontol. 2002;37:981-90.

43. Milner Y, Sudnik J, Filippi M, Kizoulis M, Kashgarian M, Stenn K. Exogen, shedding phase of the hair growth cycle: characterization of a mouse model. J Invest Dermatol. 2002;119:639-44.

44. Kishimoto J, Ehama R, Ge Y, Kobayashi T, Nishiyama T, Detmar M, Burgeson RE. In vivo detection of human vascular endothelial growth factor promoter activity in transgenic mouse skin. Am J Pathol. 2000;157:103-10.

45. Kishimoto J, Burgeson RE, Morgan BA. Wnt signaling maintains the hair-inducing activity of the dermal papilla. Genes Dev. 2000;14:1181-5.

46. Stenn KS, Paus R. Controls of hair follicle cycling. Physiol Rev. 2001;81:449-94. 
47. Randall VA, Jenner TJ, Hibberts NA, De Oliveira IO, Vafaee T. Stem cell factor/CKit signalling in normal and androgenetic alopecia hair follicles. J Endocrinol. 2008;197:11-23.

48. Hébert JM, Rosenquist T, Götz J, Martin GR. FGF5 as a regulator of the hair growth cycle: evidence from targeted and spontaneous mutations. Cell. 1994;78:1017-25.

49. Sawaya ME, Blume-Peytavi U, Mullins DL, Nusbaum BP, Whiting D, Nicholson DW et al. Effects of finasteride on apoptosis and regulation of the human hair cycle. $J$ Cutan Med Surg. 2002;6:1-9.

50. Botchkareva NV, Kahn M, Ahluwalia G, Shander D. Survivin in the human hair follicle. J Invest Dermatol. 2007;127:479-82.

51. Botchkareva NV, Ahluwalia G, Shander D. Apoptosis in the hair follicle. J Invest Dermatol. 2007;127:479-82.

52. van Scott EJ, Ekel TM. Geometric Relationships Between the Matrix of the Hair Bulb and its Dermal Papilla in Normal and Alopecic Scalp1. J Invest Dermatol. 1958:31:281-7.

53. Whiting DA. Possible mechanisms of miniaturization during androgenetic alopecia or pattern hair loss. J Am Acad Dermatol. 2001;45:S81-6.

54. Whiting DA. Advances in the treatment of male androgenetic alopecia: a brief review of finasteride studies. Eur J Dermatol. 2001;11:332-4.

55. Jahoda CA. Cellular and developmental aspects of androgenetic alopecia. Exp Dermatol. 1998;7:235-48.

56. Seiberg M, Wisniewski S, Cauwenbergh G. Shapiro SS. Trypsin-induced follicular papilla apoptosis results in delayed hair growth and pigmentation. Dev Dyn. 1997:208:553-64.

57. Randall VA. Androgens and hair growth. Dermatol Ther. 2008:21:314-28.

58. Imperato-McGinley J, Guerrero L, Gautier T, Peterson RE. Steroid $5 \alpha$-reductase deficiency in man: an inherited form of male pseudohermaphroditism. Science. 1974; $186: 1213-5$

59. Kaufman KD. Androgens and alopecia. Mol Cell Endocrinol. 2002;198:89-95.

60. Kitagawa T, Matsuda K, Inui S, Takenaka H, Katoh N, Itami S, et al. Keratinocyte growth inhibition through the modification of Wnt signaling by androgen in balding dermal papilla cells. J Clin Endocrinol Metab. 2009;94:1288-94.

61. Zimber MP1, Ziering C, Zeigler F, Hubka M, Mansbridge JN, Baumgartner M, et al. Hair regrowth following a Wnt- and follistatin containing treatment: safety and efficacy in a first-in-man phase 1 clinical trial. J Drugs Dermatol. 2011;10:1308-12.

62. Kaufman KD, Olsen EA, Whiting D, Savin R, DeVillez R, Bergfeld W, et al. Finasteride in the treatment of men with androgenetic alopecia. Finasteride Male Pattern Hair Loss Study Group. J Am Acad Dermatol. 1998:39:578-89.

63. Finasteride Male Pattern Hair Loss Study Group. Long-term (5-year) multinational experience with finasteride $1 \mathrm{mg}$ in the treatment of men with androgenetic alopecia. Eur J Dermatol. 2002;12:38-49.

64. Yeon JH, Jung JY, Choi JW, Kim BJ, Youn SW, Park KC, 5 mg/day finasteride treatment for normoandrogenic Asian women with female pattern hair loss. J Eur Acad Dermatol Venereol. 2011;25:211-4.

65. Iorizzo M, Vincenzi C, Voudouris S, Piraccini BM, Tosti A. Finasteride treatment of female pattern hair loss. Arch Dermatol. 2006;142:298-302

66. Gupta AK, Charrette A. The efficacy and safety of 5alpha-reductase inhibitors in androgenetic alopecia: a network meta-analysis and benefit-risk assessment of finasteride and dutasteride. J Dermatolog Treat. 2014;25:156-61.

67. Eun HC, Kwon OS, Yeon JH, Shin HS, Kim BY, Ro Bl,, et al. Efficacy, safety, and tolerability of dutasteride $0.5 \mathrm{mg}$ once daily in male patients with male pattern hair Ioss: a randomized, double-blind, placebo-controlled, phase III study. J Am Acad Dermatol. 2010;63:252-8.

68. Olszewska M, Rudnicka L. Effective treatment of female androgenic alopecia with dutasteride. J Drugs Dermatol. 2005;4:637-40.

69. Sawaya ME, Price VH. Different levels of 5alpha-reductase type I and II, aromatase, and androgen receptor in hair follicles of women and men with androgenetic alopecia. J Invest Dermatol. 1997;109:296-300.

70. Mahé YF, Michelet JF, Billoni N, Jarrousse F, Buan B, Commo S, et al. Androgenetic alopecia and microinflammation. Int J Dermatol. 2000:39:576-84.

71. Stefanato CM. Histopathology of alopecia: a clinicopathological approach to diagnosis. Histopathology. 2010;56:24-38.

72. Whiting DA. Diagnostic and predictive value of horizontal sections of scalp biopsy specimens in male pattern androgenetic alopecia. J Am Acad Dermatol. 1993:28:755-63.

73. Nyholt DR, Gillespie NA, Heath AC, Martin NG. Genetic basis of male pattern baldness. J Invest Dermatol. 2003:121:1561-4.

74. Bergfeld WF. Androgenetic alopecia: an autosomal dominant disorder. Am J Med 1995;98:95S-98S

75. Yazdan P. Update on the genetics of androgenetic alopecia, female pattern hair loss, and alopecia areata: implications for molecular diagnostic testing. Semin
Cutan Med Surg. 2012;31:258-66.

76. Lee R, Chang SY, Trinh H, Tu Y, White AC, Davies BS, et al. Genetic studies on the functional relevance of the protein prenyltransferases in skin keratinocytes. Hum Mol Genet. 2010;19:1603-17.

77. Ellis JA, Stebbing M, Harrap SB. Genetic analysis of male pattern baldness and the 5alpha-reductase genes. J Invest Dermatol. 1998;110:849-53.

78. Birch MP, Messenger AG. Genetic factors predispose to balding and non-balding in men. Eur J Dermatol. 2001;11:309-14.

79. Ellis JA, Harrap SB. The genetics of androgenetic alopecia. Clin Dermatol Clin Dermatol. 2001;19:149-54.

80. Ellis JA, Stebbing M, Harrap SB. Polymorphism of the androgen receptor gene is associated with male pattern baldness. $\mathrm{J}$ Invest Dermatol. 2001;116:452-5

81. el-Samahy MH, Shaheen MA, Saddik DE, Abdel-Fattah NS, el-Sawi MA, Mahran $\mathrm{MZ}$, et al. Evaluation of androgen receptor gene as a candidate gene in female androgenetic alopecia. Int J Dermatol. 2009;48:584-7.

82. Sawaya ME, Shalita AR. Androgen receptor polymorphisms (CAG repeat lengths) in androgenetic alopecia, hirsutism, and acne. J Cutan Med Surg. 1998;3:9-15.

83. Calvo RM, Asunción M, Sancho J, San Millán JL, Escobar-Morreale HE The role of the CAG repeat polymorphism in the androgen receptor gene and of skewed $X$-chromosome inactivation, in the pathogenesis of hirsutism. J Clin Endocrinol Metab. 2000;85:1735-40

84. Yip L, Zaloumis S, Irwin D, Severi G, Hopper J, Giles G, et al. Gene-wide association study between the aromatase gene (CYP19A1) and female pattern hair loss. Br J Dermatol. 2009;161:289-94.

85. Li R, Brockschmidt FF, Kiefer AK, Stefansson H, Nyholt DR, Song K, et al. Six novel susceptibility Loci for early-onset androgenetic alopecia and their unexpected association with common diseases. PLoS Genet. 2012;8:e1002746.

86. Redler S, Dobson K, Drichel D, Heilmann S, Wolf S, Brockschmidt FF, et al. Investigation of six novel susceptibility loci for male androgenetic alopecia in women with female pattern hair loss. J Dermatol Sci. 2013;72:186-8.

87. Heilmann S, Kiefer AK, Fricker N, Drichel D, Hillmer AM, Herold C, et al. Androgenetic alopecia: identification of four genetic risk loci and evidence for the contribution of WNT signaling to its etiology. J Invest Dermatol. 2013;133:1489-96.

88. Nuwaihyd R, Redler S, Heilmann S, Drichel D, Wolf S, Birch P, et al. Investigation of four novel male androgenetic alopecia susceptibility loci: no association with female pattern hair loss. Arch Dermatol Res. 2014:306:413-8.

89. Gatherwright J, Liu MT, Gliniak C, Totonchi A, Guyuron B. The contribution of endogenous and exogenous factors to female alopecia: a study of identical twins. Plast Reconstr Surg. 2012;130:1219-26.

90. Blume-Peytavi U, Blumeyer A, Tosti A, Finner A, Marmol V, Trakatelli M, et al. S1 guideline for diagnostic evaluation in androgenetic alopecia in men, women and adolescents. Br J Dermatol. 2011;164:5-15.

91. Sinclair $\mathrm{R}$, Wewerinke M, Jolley $\mathrm{D}$. Treatment of female pattern hair loss with oral antiandrogens. Br J Dermatol. 2005;152:466-73.

92. Olsen EA. The midline part: an important physical clue to the clinical diagnosis of androgenetic alopecia in women. J Am Acad Dermatol. 1999;40:106-9.

93. Olsen EA. Current and novel methods for assessing efficacy of hair growth promoters in pattern hair loss. J Am Acad Dermatol. 2003;48:253-62.

94. Hamilton JB. Patterned loss of hair in man; types and incidence. Ann N Y Acad Sci. 1951;53:708-28.

95. Lee WS, Oh Y, Ji JH, Park JK, Kim do W, Sim WY, et al. Analysis of familial factors using the basic and specific (BASP) classification in Korean patients with androgenetic alopecia. J Am Acad Dermatol. 2011;65:40-7.

96. Lee WS, Lee HJ, Choi GS, Cheong WK, Chow SK, Gabriel MT, et al. Guidelines for management of androgenetic alopecia based on BASP classification--the Asian Consensus Committee guideline. J Eur Acad Dermatol Venereol. 2013;27:1026-34.

97. Lee WS, Ro BI, Hong SP, Bak H, Sim WY, Kim do W, et al. A new classification of pattern hair loss that is universal for men and women: basic and specific (BASP) classification. J Am Acad Dermatol. 2007;57:37-46.

98. Trueb RM. Systematic approach to hair loss in women. J Dtsch Dermatol Ges. 2010;8:284-97.

99. Bi MY, Cohen PR, Robinson FW, Gray JM. Alopecia syphilitica-report of a patient with secondary syphilis presenting as moth-eaten alopecia and a review of its common mimickers. Dermatol Online J. 2009;15:6.

100. Rebora A. Acute diffuse and total alopecia of the female scalp: a new subtype of diffuse alopecia areata that has a favorable prognosis--a reply. Dermatology. 2003;207:339; author reply 340.

101. Levine N. Diffuse thinning of scalp hair. Geriatrics. 2000;55():

102. Tosti A, Peluso AM, Misciali C, Venturo N, Patrizi A, Fanti PA. Loose anagen hair. Arch Dermatol. 1997;133:1089-93.

103. Lee JY, Hsu ML. Alopecia syphilitica, a simulator of alopecia areata: histopathology and differential diagnosis. J Cutan Pathol. 1991;18:87-92.

104. Jillson OF. Alopecia. III. Diffuse hair loss (nonscarring). Cutis. 1983;31:465, 469, 472 passim 
105. Whiting DA. Chronic telogen effluvium: increased scalp hair shedding in middleaged women. J Am Acad Dermatol. 1996;35:899-906.

106. Chartier MB, Hoss DM, Grant-Kels JM. Approach to the adult female patient with diffuse nonscarring alopecia. J Am Acad Dermatol. 2002;47:809-18.

107. Miteva M, Misciali C, Fanti PA, Tosti A. Histopathologic features of alopecia areata incognito: a review of 46 cases. J Cutan Pathol. 2012;39:596-602.

108. Finner AM. Alopecia areata: Clinical presentation, diagnosis, and unusual cases. Dermatol Ther. 2011;24:348-54.

109. Priego-Recio CM, Rodríguez-Pichardo A, Camacho-Martínez FM. Unusual forms of alopecia areata in a Trichology Unit. J Eur Acad Dermatol Venereol. 2014;28:1394-6.

110. Tosti A, Piraccini BM, Sisti A, Duque-Estrada B. Hair loss in women. Minerva Ginecol. 2009;61:445-52.

111. Ross EK, Vincenzi C, Tosti A. Videodermoscopy in the evaluation of hair and scalp disorders. J Am Acad Dermatol. 2006;55:799-806.

112. Ekmekci TR, Koslu A. Phototrichogram findings in women with androgenetic alopecia. Skin Res Technol. 2006;12:309-12.

113. Ramos LD, Santili MC, Bezerra FC, Ruiz Mde F, Petri V, Patriarca MT. Dermoscopic findings in female androgenetic alopecia. An Bras Dermatol. 2012;87:691-4.

114. Rakowska A, Slowinska M, Kowalska-Oledzka E, Olszewska M, Rudnicka L. Dermoscopy in female androgenic alopecia: method standardization and diagnostic criteria. Int J Trichology. 2009:1:123-30.

115. Deloche C, de Lacharrière 0, Misciali C, Piraccini BM, Vincenzi C, Bastien P, et al. Histological features of peripilar signs associated with androgenetic alopecia. Arch Dermatol Res. 2004;295:422-8.

116. Gassmueller J, Rowold E, Frase T, Hughes-Formella B. Validation of TrichoScan technology as a fully-automated tool for evaluation of hair growth parameters. Eur J Dermatol. 2009;19:224-31

117. Hoffmann R. TrichoScan: combining epiluminescence microscopy with digital image analysis for the measurement of hair growth in vivo. Eur $\mathrm{J}$ Dermatol. 2001:11:362-8

118. Kantor J, Kessler LJ, Brooks DG, Cotsarelis G. Decreased serum ferritin is associated with alopecia in women. J Invest Dermatol. 2003;121:985-8.

119. Rushton DH, Ramsay ID. The importance of adequate serum ferritin levels during oral cyproterone acetate and ethinyl oestradiol treatment of diffuse androgendependent alopecia in women. Clin Endocrinol (Oxf). 1992;36:421-7.

120. Trost LB, Bergfeld WF, Calogeras $E$. The diagnosis and treatment of iron deficiency and its potential relationship to hair loss. J Am Acad Dermatol. 2006:54:824-44.

121. Futterweit W, Dunaif A, Yeh HC, Kingsley P. The prevalence of hyperandrogenism in 109 consecutive female patients with diffuse alopecia. J Am Acad Dermatol. 1988; $19: 831-6$

122. Freinkel RK, Freinkel N. Hair growth and alopecia in hypothyroidism. Arch Dermatol. 1972;106:349-52

123. Rasheed H, Mahgoub D, Hegazy R, El-Komy M, Abdel Hay R, Hamid MA, et al. Serum ferritin and vitamin d in female hair loss: do they play a role? Skin Pharmacol Physiol. 2013;26:101-7.

124. Amor KT, Rashid RM, Mirmirani P. Does D matter? The role of vitamin D in hair disorders and hair follicle cycling. Dermatol Online J. 2010;16:3

125. Malloy PJ, Feldman D. The role of vitamin D receptor mutations in the development of alopecia. Mol Cell Endocrinol. 2011;347:90-6.
126. Lever WF, Elder DE, Elenitsas R, Johnson BL, Murphy GF. Lever's histopathology of the skin. 9th ed. Philadelphia: Lippincott Williams \& Wilkins; 2009.

127. Penha MÁ, Santos PM, Miot HA. Dimensioning the fear of dermatologic diseases. An Bras Dermatol. 2012:87:796-9.

128. Dolte KS, Girman CJ, Hartmaier S, Roberts J, Bergfeld W, Waldstreicher J. Development of a health-related quality of life questionnaire for women with androgenetic alopecia. Clin Exp Dermatol. 2000;25:637-42.

129. Tsuboi R, Itami S, Inui S, Ueki R, Katsuoka K, Kurata S, et al. Guidelines for the management of androgenetic alopecia (2010). J Dermatol. 2012;39:113-20.

130. Gupta AK, Daigle D. The use of low-level light therapy in the treatment of androgenetic alopecia and female pattern hair loss. J Dermatolog Treat. 2014;25:162-3.

131. Levy LL, Emer JJ. Female pattern alopecia: current perspectives. Int J Womens Health. 2013;5:541-56.

132. Vogel JE, Jimenez F, Cole J, Keene SA, Harris JA, Barrera A, et al. Hair restoration surgery: the state of the art. Aesthet Surg J. 2013;33:128-51.

133. Unger RH. Female hair restoration. Facial Plast Surg Clin North Am. 2013;21:407-17.

134. Bagatin E, Miot HA. How to design and write a clinical research protocol in Cosmetic Dermatology. An Bras Dermatol. 2013;88:69-75

\begin{tabular}{l}
\hline M AILING ADDRESS: \\
H élio A mante M iot \\
D epartamento de D ermatologia e Radioterapia \\
FM B-U nesp, SN \\
Campus universitário de Rubião Jr. \\
18618-000, Botucatu - SP, Brazil. \\
E-mail: heliomiot@fmb.unesp.br
\end{tabular}

M AILING ADDRESS:

FM B-U nesp, SN

18618-000, Botu catu - SP, Brazil.

-mail: heliomiot@fmb.unesp.br

Como citar este artigo: Ramos PM, Miot HA. Female Pattern Hair Loss: a clinical and pathophysiological review An Bras Dermatol. 2015;90(4):529-43. 